\title{
Evaluation of mucin histochemistry in benign and malignant prostatic lesion and their correlation PSA level
}

\section{Bastola $\mathrm{S}^{1}$, Talwar $\mathrm{OP}^{2}$}

${ }^{I}$ Department of Pathology, Manipal Teaching Hospital, Pokhara, Nepal.

${ }^{2}$ Department of Pathology, Manipal Teaching Hospital, Pokhara, Nepal.

\section{Keywords: \\ Prostate; Neoplasm; Prostatic Density; Prostatic Volume.}

\begin{abstract}
Background: The major causes of prostatic enlargement are nodular hyperplasia, prostatitis and neoplasm including prostatic intraepithelial neoplasm. Acidic mucin is absent in benign prostatic glands and is present in some prostatic adenocarcinomas. Mucin stain may be an adjunctive aid in the diagnosis of prostatic adenocarcinoma. This study aims to find out role of acidic mucin in differentiating benign and malignant lesion together with the aid of PSA level.
\end{abstract}

Materials and Methods: A study was done from August 2006 to August 2008. Serum PSA level was performed. Biopsy specimen were processed and stained with Hematoxylin and Eosin as well as Alcian Blue and Periodic Acid Schiff. Data was coded and entered into SPSS v. 11 and Chi-square test and scatter plot was done to analyze the findings.

RESULTS: Out of 207 prostatic specimens studied, 78.3\% showed BPH with or without prostatitis whereas $12 \%$ showed PIN and $8.7 \%$ malignancy. PSA density showed statistical significance with $\mathrm{p}=$ 0.02 , in favor of malignancy. Alcian blue positivity was in $77.8 \%$ of malignant cases and $18.5 \%$ in benign cases $(p=0.000003)$. Acid mucin was more in well differentiating tumours decreasing significantly in high grade malignancies. Combined diagnostic value of PSA $>10 \mathrm{ng} / \mathrm{ml}$ and Alcian blue positivity showed increase in specificity to $96.8 \%$ for diagnosing a malignant lesion, with positive predictive value of $57.1 \%$.

CONCLUSION: PSA density can be used to identify and pick up malignant cases where intermediate levels of PSA values are common. Alcian blue stain can help in assessing the degree of differentiation in malignant cases.

\section{INTRODUCTION}

Enlargement of prostate is one of the leading cause of morbidity in all men after the age of 40 years. The major causes are nodular hyperplasia, prostatitis and neoplasm

\section{Correspondence:}

Dr. Shovha Bastola, MD

Department of Pathology,

Grande International Hospital, Kathmandu, Nepal

E-mail:shovabastola@hotmail.com including prostatic intraepithelial neoplasm. By far the most common is nodular hyperplasia of the prostate which can be seen in approximately $20 \%$ of men 40 years of age, a figure that increases to $70 \%$ by age 60 and to $90 \%$ by age 70. ${ }^{1}$ Prostatitis is another important cause seeking medical attention. Internationally, there is an increased incidence of mycobacterial prostatitis, concomitant with disseminated disease, in underdeveloped countries. 
The prostatic cancer is the second most common cause of cancer death in men and is the fourth most common male malignancy worldwide. ${ }^{2}$ It is estimated that more than 300,000 new cases are detected anually of which approximately 41,000 prove to be fatal. ${ }^{3}$ Prostatic intraepithelial neoplasia (PIN) has been identified as a precursor lesion to prostatic carcinoma. ${ }^{4} \mathrm{PIN}$ has a high predictive value as a marker for adenocarcinoma, and its identification warrants repeat biopsy for concurrent or subsequent invasive carcinoma.

Numerous reports have claimed that because acidic mucin is absent in benign prostatic glands and is present in some prostatic adenocarcinomas, this stain may be an adjunctive aid in the diagnosis of adenocarcinoma of the prostate. ${ }^{5}$

This study was under taken to find out role of mucin in differentiating benign and malignant lesion together with the aid of other investigations like PSA level and clinicoradiological correlates.

\section{MATERIALS AND METHODS}

This was an analytical study done from August 2006 to August 2008 of patients who underwent prostatic biopsies and surgeries due to various prostatic pathologies in Manipal Teaching Hospital. Biopsy specimen included were trucut biopsy, suprapubic prostatectomy, TURP specimen. Histopathological sections were stained by Hematoxylin and Eosin for microscopic features and special stains were done with Alcian Blue and Periodic Acid Schiff (PAS). Serum of these patients was collected for prostatic specific antigen (PSA) where possible. Relevant clinical data were collected. Data was coded and entered into SPSS (Software Programme For Statistical Study) version 11 and analysed. Chi-square test was used to calculate the significance for categorized variables. Scatter plot was done to see the distribution of PSA in different prostatic lesions.

\section{RESULTS}

A total of 207 cases of patients of prostatism were studied during the period of two years. The mean age of patients was $70.22 \pm 9.84$, the range from 36 years to 97 years. Maximum cases were from age group 70-79 years constituting $42 \%$ $(n=87)$ of total cases followed by age group between 60-69 years $35.1 \%(n=57)$.

The major histopathological divisions were done for Benign, PIN and malignant cases. A total of 162 cases of benign lesions, 27 of PIN and 18 of malignant cases were identified histopathologically. The age group distribution of the various prostatic lesions is depicted in the table 1 .

Out of these, $(n=72) 34.8 \%$ were found to have benign prostatic hyperplasia, 43.5\% $(\mathrm{n}=90)$ benign prostatic hyperplasia with chronic prostatitis, $12 \%(n=27)$ PIN and
$8.7 \%(n=18)$ malignancy.

Of the total PIN cases most of the cases were diagnosed as PIN - low grade (22/27) and among malignant cases 2 were well differentiated, 8 were moderately differentiated, 8 were poorly-differentiated adenocarcinomas.

\section{Prostatic specific antigen and histopathology.}

Prostatic specific antigen (PSA) was done in total of 63 patients out of which 45 were in benign conditions, 11 in malignant conditions and 7 in PIN cases. PSA distribution in different prostatic lesions is depicted in the following table 2 .

When cut off of PSA value was taken as $10 \mathrm{ng} / \mathrm{ml}, 90.9 \%$ of malignancy showed PSA $>10$, and $44.5 \%$ of benign lesions still had PSA value $>10 \mathrm{ng} / \mathrm{ml}$, which was statistically significant in favor of malignancy, with $\mathrm{p}=0.01$ (chi-square of 5.92)

\begin{tabular}{|c|c|c|c|c|}
\hline $\begin{array}{c}\text { Age } \\
\text { Group }\end{array}$ & Malignant & Benign & PIN & Total \\
\hline$<50$ & $1(5.6 \%)$ & $4(2.46 \%)$ & - & 5 \\
\hline $50-59$ & - & $13(8 \%)$ & $3(11.1 \%)$ & 16 \\
\hline $60-69$ & $6(33.3 \%)$ & $57(35.1 \%)$ & $6(22.2 \%)$ & 69 \\
\hline $70-79$ & $9(50 \%)$ & $68(41.9 \%)$ & $10(37.1 \%)$ & 87 \\
\hline$>80$ & $2(11.1 \%)$ & $20(12.3 \%)$ & $8(29.6 \%)$ & 30 \\
\hline Total & 18 & 162 & 27 & 207 \\
\hline
\end{tabular}

Table 2: PSA level versus histopathology

\begin{tabular}{lllll}
\hline $\begin{array}{l}\text { PSA Level } \\
(\mathbf{n g} / \mathbf{m l})\end{array}$ & Malignant & Benign & PIN & Total \\
\hline$<4$ & - & 10 & 1 & 11 \\
\hline $4-10$ & 1 & 15 & 3 & 19 \\
\hline $10-20$ & 1 & 12 & 1 & 14 \\
\hline $20-50$ & 5 & 7 & 2 & 14 \\
\hline 50 & 4 & 1 & - & 5 \\
\hline Total & 11 & 45 & 7 & 63 \\
\hline
\end{tabular}

Table 3: Diagnostic value of prostatic malignancy at various levels of PSA

\begin{tabular}{llll}
\hline $\begin{array}{l}\text { Serum } \\
\text { PSA(ng/ml) }\end{array}$ & Sensitivity & Specificity & $\begin{array}{l}\text { Positive } \\
\text { predictive value }\end{array}$ \\
\hline$>=4$ to $<10$ & $100 \%$ & $21.2 \%$ & $21.2 \%$ \\
\hline$>=10$ to $<20$ & $90.9 \%$ & $55.8 \%$ & $30.3 \%$ \\
$>=20$ to $<50$ & $81.8 \%$ & $82 \%$ & $53 \%$ \\
$>=50$ & $36.4 \%$ & $98.1 \%$ & $80 \%$
\end{tabular}


Table 4: Correlation of PSA density with histopathology

\begin{tabular}{lllll}
\hline $\begin{array}{l}\text { PSA density } \\
(\mathbf{n g} / \mathbf{m l} / \mathbf{c m} 3)\end{array}$ & Malignant & Benign & PIN & Total \\
\hline$<0.15$ & $1(11.1 \%)$ & $16(57.1 \%)$ & $2(50 \%)$ & 19 \\
$>0.15$ & $8(88.9 \%)$ & $12(42.9 \%)$ & $2(50 \%)$ & 22 \\
Total & 9 & 28 & 4 & 41 \\
\hline
\end{tabular}

Table 5: Mucin stains in Prostatic lesions

\begin{tabular}{llll}
\hline Histopathology & PAS positive & $\begin{array}{l}\text { Alcian Bleu } \\
\text { positive }\end{array}$ & $\begin{array}{l}\text { Positive } \\
\text { predictive value }\end{array}$ \\
\hline Carcinoma & $8(44.4 \%)$ & $14(77.8 \%)$ & $21.2 \%$ \\
Benign & $142(87.8 \%)$ & $30(18.5 \%)$ & $30.3 \%$ \\
PIN & $24(88.8 \%)$ & $5(18.5 \%)$ & $53 \%$
\end{tabular}

PAS negativity with malignancy $\chi 2=18.78, d f=1, p=0.00068$

$A B$ positivity with malignancy $\chi 2=30.03, d f=1, p=0.000003$

While evaluating the sensitivity and specificity of particular cut offs, PSA $>=50 \mathrm{ng} / \mathrm{ml}$ had specificity of $98 \%$ but had sensitivity of just $36 \%$, whereas PSA $>10$ $\mathrm{ng} / \mathrm{ml}$ had $55.8 \%$ specific and $90.9 \%$ sensitive .When cut off value of PSA $>20 \mathrm{ng} / \mathrm{ml}$ was taken the sensitivity and specificity for picking up malignancy was both $82 \%$, so for our endogenous population the PSA value of more than $20 \mathrm{ng} / \mathrm{ml}$ most likely can be taken for diagnosing malignant cases.(Table 3)

The PSA density was calculated in both the benign histological conditions and malignancy and shown in table 4. There was statistical significance of PSA density $>0.15$ $\mathrm{ng} / \mathrm{ml} / \mathrm{cm} 3$ in malignancy as compared to benign lesions with $\mathrm{p}=0.02$ (Fischer exact test)

\section{Mucin Stains in Prostatic Pathologies:}

PAS positivity and Alcian blue positivity in benign, PIN and carcinoma cases are showin in table 5. P value for PAS negativity in malignancy is 0.00068 which is statistically significant. $\mathrm{P}$ value for $\mathrm{AB}$ positivity in malignancy is 0.000003 which is again statistically significant for diagnosis of malignancy. Combined Diagnostic value of PSA>10ng/ $\mathrm{ml}$ and Alcian Blue positivity in Malignancy:

Since PSA $>10 \mathrm{ng} / \mathrm{ml}$ was seen in majority of malignant cases and Alcian blue was seen in most of the malignant cases so combined diagnostic value of both of these together was analysed which showed high statistical significance with $\mathrm{p}<0.0001$. Serum PSA and Alcian blue positive in malignancy has significant chi-square value $(\chi 2=41.35$, $\mathrm{df}=1$ ). It was also observed that Alcian blue positivity decreased with the decrease in differentiation showing positivity in only $50 \%$ of high grade prostatic carcinoma. In low grade and intermediate grade prostate cancers, however, all were alcian blue stain positive.

\section{DISCUSSION}

During the study period, 207 patients with history of enlarged prostate were studied. Most of the cases were found out to be Nodular hyperplasia of Prostate with chronic prostatitis, followed by Nodular hyperplasia of prostate alone in $43.5 \%$ and $34.8 \%$ respectively, followed by PIN I and prostatic carcinoma in $10.6 \%$ and $8.7 \%$

Result of the present study shows $90.9 \%$ of malignant lesion had PSA $>10 \mathrm{ng} / \mathrm{ml}$ with sensitivity of $90.9 \%$ and specificity of $55.8 \%$, When cut off of $50 \mathrm{ng} / \mathrm{ml}$ was taken it had specificity of $98 \%$ but had sensitivity of just $36 \%$ for malignancy.

In a study done by Arista-Nasr $\mathrm{J}$ et $\mathrm{al}^{6}$ in Mexico median PSA values was $11.2 \mathrm{ng} / \mathrm{ml}$ in benign cases and $45.6 \mathrm{ng} / \mathrm{ml}$ in malignancy. There was a considerable overlap of PSA levels in benign and malignant cases and only values above $30 \mathrm{ng} / \mathrm{ml}$ were highly suggestive of malignancy. A study performed by Gerstenbluth RE et. $\mathrm{al}^{7}$ University School of Medicine, Ohio, USA, demonstrated that serum PSA > $50 \mathrm{ng} / \mathrm{ml}$ was $98.5 \%$ accurate in predicting the presence of prostatic carcinoma in tissue biopsy which was consistent with our finding of $98 \%$ specificity. In our study PSA was higher than $10 \mathrm{ng} / \mathrm{ml}$ almost $44.2 \%$ benign diseases and majority of these cases were Nodular hyperplasia of Prostate with prostatitis. In these cases the sensitivity would have been better if these cases of suspected prostatitis were treated with course of antibiotic and reevaluated for PSA value.

In chronic prostatitis various proposed mechanisms of elevation of PSA include leakage of PSA into the blood stream, hypervascularity, and altered vascular permeability secondary to inflammation as described by Sindhwani et al. ${ }^{8}$ Evidence from the literature indicates that antimicrobial treatment may lower the PSA levels to what is considered the normal range. Despite that, general recommendations for the practical management are lacking and undetected prostate cancer in men with chronic prostatitis remains a difficult issue. ${ }^{9}$

In our study since most of the biopsies were having features of chronic prostatitis PSA was considerably high so screening with cut off of PSA $>4 \mathrm{ng} / \mathrm{ml}$ would be misleading and will require lot of biopsy, hence PSA after treatment would be recommended and the PSA cut off for our own endogenous population will be important for screening program.

The concept of PSA density is based on the assumption that, as non-neoplastic prostate tissue does leak some PSA into the circulation, for PSA to be useful in diagnosing prostate 
cancer, values should be corrected for total gland volume. Transrectal ultrasound is used to produce an estimate of gland volume and a threshold of 0.15 has been suggested as being discriminatory for cancer. ${ }^{10}$

In this study $88.9 \%$ of malignancy showed PSA density $>0.15 \mathrm{ng} / \mathrm{ml} / \mathrm{cm}^{3}$ which was statistically significant with $\mathrm{p}$ value of 0.02 in favor of malignancy. PSA density was a better predictor of prostate cancer in Chinese men with PSA levels of 4-10 ng/ml as shown by Zheng XY et $\mathrm{al}^{11}$, especially those who have had prior ultrasound-determined measurements of prostate volume. PSA density was a significantly better indicator of prostate cancer than $\mathrm{f} / \mathrm{t}$ PSA. The sensitivity and specificity of PSA density at a cutoff of $0.134 \mathrm{ng} / \mathrm{ml} / \mathrm{cm}^{3}$ was $90 \%$ and $33.7 \%$, respectively. Similar findings were observed in other studies. ${ }^{12,13}$

In benign lesions $87.8 \%$ cases were PAS positive and $18.5 \%$ were Alcian blue positive while in cases of carcinoma prostate Alcian blue positivity was seen in $77.8 \%$ of cases as compared $44.4 \%$ which were PAS positive. This finding is because of the fact that acid mucosubstances are produced more by carcinoma than by benign prostates. Our findings are in consistent with previous studies done by Hukill and Vidone et $\mathrm{al}^{14}$ who reported $80 \%$ Alcian positivity in carcinoma prostate cases. Similar study done by Mathur SK et $\mathrm{al}^{15}$ showed neutral mucin was more frequently seen in BPH 93.3\% as compared to carcinoma 36\% while acid mucin was found in more cases of carcinoma prostate 68 $\%$ as compared to benign prostatic lesion in $16 \%$. They also observed that the positivity of Alcian blue was more in well differentiated tumor decreasing significantly in high grade malignancies. Luna -More $\mathrm{S}$ et $\mathrm{al}^{16}$ studied 130 cases of prostatic carcinomas and 22 cases of atypical adenomatous hyperplasia $(\mathrm{AAH})$ for neutral and acid mucins and found that incidence of acid mucin was higher in Prostatic carcinoma.

In our study we observed that alcian blue positivity was seen in $100 \%$ cases of low grade and intermediate grade prostatic carcinoma with Gleason score of 2-7 but the alcian blue positivity dropped to $50 \%$ in high grade prostatic carcinoma with Gleason score $>8$, showing that in poorly differentiated carcinoma alcian blue positivity is less. This finding was in consistent with study by Mathur et al and Taylor et al. ${ }^{15,17}$ The other observation that was made in this study was combining the alcian blue positivity with PSA value cut off of $>10 \mathrm{ng} / \mathrm{ml}$, showed a high specificity for malignancy, $96.8 \%$ specific for malignancy.

\section{CONCLUSION}

Mucin stains like Alcian blue and PAS helps to identify malignant cases and specificity will be increased to $96.8 \%$ combining the Alcian blue positivity in cases of PSA $>10 \mathrm{ng} /$ $\mathrm{ml}$. PSA density may be helpful in differentiating nodular hyperplasia of prostate, prostatitis with carcinoma prostate.
A larger population based prospective study is required to find out the cutoff value for taking biopsy after a screening PSA for our endogenous population so that cases of prostatic carcinoma are identified in earlier stage and treatment can be started promptly.

\section{REFERENCES}

1. Kumar V, Abbas AK, Fausto N,editor. Pathologic Basis of disease. Seventh Edition. Saunders: Philadelphia; 2004. 1525pp.

2. Mott LJ. Squamous cell carcinoma of the prostate. Report of 2 cases and review of the literature. J Urol. 1979;121:833-5. PMid:458967

3. Boring LL, Squires TS, Tong T. Cancer statistics 1994. Cancer J Clin. 1994;44:7. Crossref

4. Epstein JI. What's new in prostate cancer disease assessment in 2006? Curr Opin Urol. 2006 May;16:146-51. Crossref

5. Epstein JI, Fynheer J. Acidic mucin in the prostate: can it differentiate adenosis from adenocarcinoma? Hum Pathol. 1992;23:1321-5. Crossref

6. Arista- Nasr J, et al. Serum level of prostatic specific antigen in 100 patients with prostatic biopsy. Rev Invest Clin. 1998;50:487-90. PMid: 10070220

7. Gerstenbluth RE, Seftel AD, Hampel NO, Oefelein MG, Resnick M1. The accuracy of the increased prostate specific antigen level (greater than a equal to $20 \mathrm{ng} / \mathrm{ml}$ ) in predicting prostate cancer; is biopsy always required? J Urol 2002 Nov;164-8.

8. Sindhwani P, Wilson CM. Prostatitis and serum prostate-specific antigen. Curr Urol Rep. 2005 Jul;6:307-12. Crossref

9. Hochreiter WW. The issue of prostate cancer evaluation in men with elevated prostate-specific antigen and chronic prostatitis. Andrologia. 2008 Apr;40:130-3. Crossref

10. 38. Benson MC, Whang IS, Olsson CA, et al. The use of prostate specific antigen density to enhance the predictive value of intemediate levels of serum prostate specific antigen. J Urol 1992;147:817-21.

11. Zheng XY, Xie LP, Wang YY et al. J Cancer Res Clin Oncol. 2008 Nov;134:1207-10. doi: 10.1007/s00432-008-0400-8. Crossref

12. Tanaka N, Fujimoto K, Chihara Y, Torimoto M, Hirao Y, Konishi N, Saito I. Prostate Cancer Prostatic Dis. 2007;10:274-8. Crossref

13. Kobayashi T, Kawahara T, Nishizawa K, Ogura K, Mitsumori K, Ide Y. Int J Urol. 2005;12:881-5. Crossref Crossref

14. Franks LM, OsheaJD, Thompson AER. Mucin in Prostate -a histochemical study in normal gland, latent, clinical and colloid cancer. Cancer 1964;17:983-91. Crossref 
15. Mathur SK, Gupta S, Marwah N, Narula A, Singh s, Arora B. Significance of mucin stain in differentiating benign and malignant lesions of the prostate. Indian J pathol Microbiol 2003;46:593-5. PMid:15025351

16. Luna -More S,Floez P,Ayala A,Diaz F,Santos A.Neutral and Acid mucins and eosinophil and argyrophil crystalloids in carcinoma and atypical adenomatous hyperplasia of prostate. Pathol Res Pract 1997;193:291-8. Crossref

17. Taylor NS.Histochemistry in the diagnosis of early prostatic carcinoma.Human Pathol 1979;10:513-20. Crossref 